\title{
COMPARISON OF THIOPENTONE SODIUM AND PROPOFOL AS INDUCTION AGENTS IN MODIFIED ELECTROCONVULSIVE THERAPY IN HAEMODYNAMIC STATUS AND SEIZURE DURATION- A PROSPECTIVE DOUBLE-BLIND RANDOMISED CONTROLLED TRIAL
}

\author{
Shoukkathali Anzar1, Sheela Verghese2, D. Raju3, Mumthas Abdul Rasheed ${ }^{4}$ \\ ${ }^{1}$ Assistant Professor, Department of Anaesthesiology, Government Medical College, Kollam. \\ ${ }^{2}$ Associate Professor, Department of Anaesthesiology, Government Medical College, Thiruvananthapuram. \\ ${ }^{3}$ Professor, Department of Psychiatry, Government Medical College. \\ 4Junior Specialist, Department of ENT, Taluk Hospital, Varkala.
}

ABSTRACT

\section{BACKGROUND}

The essential elements of anaesthesia for Modified Electroconvulsive Therapy (mECT) include rapid loss of consciousness, effective attenuation of the hyperdynamic response to the electrical stimulus, avoidance of gross movements, minimal interference with seizure activity and prompt recovery of spontaneous ventilation and consciousness.

The aim of the study is to compare the haemodynamic variations in modified ECT using Thiopentone sodium and Propofol as induction agents.

\section{MATERIALS AND METHODS}

80 patients posted for mECT were selected randomly from the Department of Psychiatry, Government Medical College, Thiruvananthapuram; 40 patients were given Thiopentone sodium $4 \mathrm{mg} / \mathrm{kg}$ and 40 patients were given Inj. Propofol $1 \mathrm{mg} / \mathrm{kg}$ as induction agents. The variables like Heart Rate, Systolic and Diastolic Blood Pressure were measured at 0 minute, 2 minutes, 4 minutes, 6 minutes, 8 minutes, 10 minutes, 15 minutes and 30 minutes after induction of anaesthesia. The outcome measures compared are Rate Pressure Product and Duration of Seizure Threshold.

\section{RESULTS}

The mean seizure duration for both groups were comparable (Thiopentone group $31.95 \pm 9.59$ sec and Propofol group $32.83 \pm$ $6.18 \mathrm{sec}$, P value > 0.05). There was a very highly significant reduction in Rate Pressure Product (RPP) for Propofol group compared to Thiopentone group at $2^{\text {nd }} \mathrm{mt}, 4^{\text {th }} \mathrm{mt}, 8^{\text {th }} \mathrm{mt}, 10^{\text {th }} \mathrm{mt}$ and $30^{\text {th }} \mathrm{mt}(\mathrm{p}<0.001)$.

\section{CONCLUSION}

We conclude that Propofol when compared to Thiopentone sodium is a safe anaesthetic agent for electroconvulsive therapy with good haemodynamic stability.

\section{KEYWORDS}

mECT, Propofol, Thiopentone Sodium, Haemodynamic Stability.

HOW TO CITE THIS ARTICLE: Anzar S, Verghese S, Raju D, et al. Comparison of thiopentone sodium and propofol as induction agents in modified electroconvulsive therapy in haemodynamic status and seizure duration- a prospective double-blind randomised controlled trial. J. Evolution Med. Dent. Sci. 2017;6(33):2719-2725, DOI: 10.14260/Jemds/2017/587

\section{BACKGROUND}

Use of anaesthesia has become the standard of modern day Modified Electroconvulsive Therapy (MECT) practice. Anaesthesia during electroconvulsive therapy has given the psychiatrists a more humane and ethical way to practice their profession. It gives the patients a good and safer option during the treatment. Lot of studies has undergone in this subject to find out the better agents for induction of anaesthesia, so that it balances between good patient safety and effectiveness of the treatment.

Financial or Other, Competing Interest: None.

Submission 10-03-2017, Peer Review 12-04-2017,

Acceptance 18-04-2017, Published 24-04-2017.

Corresponding Author:

Dr. Shoukkathali Anzar,

SRA 38, Tc 12/1222,

Law College Junction

Vikas Bhavan PO,

Thiruvananthapuram - 695033,

Kerala.

E-mail: anzarshouk@gmail.com

DOI: $10.14260 /$ jemds $/ 2017 / 587$
The usual induction agents used for MECT are methohexital, thiopentone sodium, propofol, etomidate or sometimes ketamine. However, information about doses of anaesthetic agents for Indian patients is lacking.

A lot of study were done to titrate the ideal anaesthetic agent for MECT to balance between haemodynamic variability and seizure duration to get a clinically significant response. Efficacy of ECT in alleviating acute depression is dependent on the duration of the induced seizure.(1,2) EEG seizure activity lasting from 25 to 50 is alleged to produce the optimal antidepressant response. Patients experiencing an initial seizure duration of $15 \mathrm{sec}$ or $120 \mathrm{sec}$ achieve a less favourable response to ECT.(3)

Thiopentone and Propofol in various doses were studied. Here, we are comparing the haemodynamic variations and seizure duration between Thiopentone sodium and Propofol as agents in modified electroconvulsive therapy.

Because many of the anaesthetic drugs used for ECT have anticonvulsant properties, they would be expected to decrease the duration of ECT-induced seizure activity in a dose-dependent manner. Use of larger than necessary dosages of general anaesthetics will shorten the duration of 
ECT-induced seizure activity and could adversely affect the efficacy of the ECT treatments. Therefore, there is a delicate balance between achieving an adequate anaesthetic state and an optimal duration of EEG seizure activity. ${ }^{(4)}$ In the current healthcare environment, use of general anaesthetic techniques with a rapid onset and recovery is essential to facilitate fast tracking and permits the discharge of these patients within 1 - 2 hrs. after the ECT treatment.

\section{The Aim of the Study is to Compare}

1. Haemodynamic status between Thiopentone Sodium and Propofol as induction agents in MECT.

2. To compare the seizure duration.

\section{MATERIALS AND METHODS}

After obtaining the Ethical Committee and Research Committee clearance, 80 patients posted for MECT in the Department of Psychiatry, Government Medical College, Thiruvananthapuram were recruited for the study by a computer generated random number table into two groups.

Group T- Those receiving Inj. Thiopentone sodium $4 \mathrm{mg} / \mathrm{kg}$ I/V.

Group P- Those receiving Inj. Propofol $1 \mathrm{mg} / \mathrm{kg} \mathrm{I/V}$.

All patients included in the study underwent a detailed preanaesthetic checkup.

The age and weight were noted with baseline heart rate, the systolic and diastolic blood pressure. All patients and nearest relatives were given a written informed consent.

\section{Premedication}

Each patient was given T. Ranitidine $150 \mathrm{mg}$ in the previous night and T. Metoclopramide $10 \mathrm{mg}$ and T. Ranitidine $150 \mathrm{mg}$ at $6.00 \mathrm{am}$ in the morning of the procedure. The patient was asked to keep nil orally for 8 hours prior to the procedure. Patient was asked to avoid T. Lithium in the night prior to the procedure.

Secured an intravenous line with $18 \mathrm{~g}$ cannula in the right arm. Inj. Glycopyrrolate $0.2 \mathrm{mg}$ intramuscular is given 1 hour before the procedure. The fluid deficit was calculated according to the hours of fasting $2 \mathrm{~mL} / \mathrm{kg} /$ hour. The deficit was corrected with $0.9 \%$ normal saline over 2 hours.

\section{Monitors}

Patients were connected to the non-invasive blood pressure monitor using the standard adult size cuff on the right arm, Electrocardiogram monitor. The baseline systolic and diastolic blood pressure taken and calculated the mean arterial pressure,

$\mathrm{MAP}=$ Diastolic blood pressure $+1 / 3$ pulse pressure,

Pulse Pressure $=$ Systolic blood pressure - Diastolic blood pressure-

- $\quad$ Rate Pressure Product is calculated using the formula.

- $\mathrm{RPP}=$ Systolic blood pressure $\times$ Heart rate

- The baseline heart rate is measured from the ECG machine, another standard adult size blood pressure cuff of a sphygmomanometer is applied on the left upper arm, which is used as a tourniquet.

\section{Procedure}

Patients were preoxygenated with $100 \%$ oxygen through Magill's circuit and anatomical face mask for 5 minutes. The inducing drug (Either Thiopentone Sodium or Propofol) in a masked syringe by an Anaesthetist who is blind to the group is given intravenously through the side port of the cannula over an on flow infusion of $0.9 \%$ normal saline slowly over 30 seconds. The tourniquet in the left arm is inflated $30 \mathrm{mmHg}$ above the recorded systolic blood pressure with the sphygmomanometer. The loss of eye lash reflex is taken as the end point of induction. Supporting the ventilation with intermittent positive pressure ventilation using the Magill's circuit. Give Inj. Succinylcholine intravenously and support the ventilation using the bag and mask. The dose of Inj. Succinylcholine $0.5 \mathrm{mg} / \mathrm{kg}+/$ - is titrated in the first session of the MECT. Support the ventilation with $100 \%$ oxygen via bag and mask by intermittent positive ventilation. A soft rubber bite block is introduced into the oral cavity to protect the tongue from injury during the seizure. If the jaw relaxation is not adequate, bag and mask ventilation is continued till adequate relaxation is obtained and then the bite block is introduced. Bilateral ECT is administered over the temple of the head after cleaning the area with saline, the threshold of the stimulus is measured in the first ECT session by titration. Look for the seizure activity in the left hand, which is already isolated using the sphygmomanometer with a stop watch. Adequate seizure was defined as 15 seconds of motor and 25 seconds of EEG seizure (Electroencephalogram). After the seizure, the bite block is removed, cleared the oral secretions with soft tipped suction catheter by venturi suction and continued the assisted ventilation by bag and mask with $100 \%$ oxygen till the patient takes independent smooth regular respiration. Continue the oxygen supplementation via the simple face mask. The heart rate, systolic and diastolic blood pressure and seizure duration were measured and calculated the MAP. Rate Pressure Product (RPP), which is the measure of myocardial oxygen demand is also calculated.

\section{Management of Complications}

Any episode of bradycardia is treated with Inj. Atropine 0.6 mg intravenously. Hypotension is treated with $0.9 \%$ normal saline infusion. Nausea or vomiting is treated with Inj. Ondansetron $4 \mathrm{mg}$ intravenously. Any signs of breathing difficulty or bronchospasm are treated.

\section{Statistical Analysis}

A pilot study was conducted to find out the minimum drug needed to get comparable haemodynamic status balancing absence of awareness following MECT. Level of significanceIt is taken as $5 \%$.

Power is taken as $80 \%$. Clinically meaningful differenceTo detect a smaller difference. Sample size is calculated by determining the population (500), confidence interval 11 secs for seizure duration for a clinically significant effect and confidence limit of $95 \%$ and referring the prior studies using the software developed by the Christian Medical College (CMC), N Master version 2.0. Formula of calculating sample size is-

$\mathrm{n}=\left[\left(\mathrm{Z}_{\alpha / 2}+\mathrm{Z}_{\beta}\right)^{2} \times\left\{2\left(\right.\right.\right.$ ó $\left.\left.^{2}\right\}\right] /(\mu 1-\mu 2)^{2}$

where,

$\mathrm{n}=$ sample size required in each group,

$\mu 1=$ mean change dose of Thiopentone to produce a clinically meaningful change in $\mathrm{EEG}=10$

$\mu 2=$ mean change in dose of Propofol to produce a clinically meaningful $\mathrm{EEG}=9.4$.

$\mu 1-\mu 2=$ clinically significant difference $=0.6$ 
ó= standard deviation= 1.195 .

$\mathrm{Z}_{\alpha / 2}$ : This depends on level of significance, for $5 \%$ this is 1.96

$Z_{\beta}$ : This depends on power, for $80 \%$ this is 0.84

The ' $n$ ' comes as 90 and accepting the dropout as $10 \%$ we assume the sample size for detecting a meaningful change in EEG can be achieved with 80 patients, i.e. 40 patients in each group.

Data were analysed using computer software, Statistical Package for Social Sciences (SPSS) version 10. Data are expressed in its frequency and percentage. To elucidate the associations and comparisons between different parameters, Chi-square $\left(\chi^{2}\right)$ test was used as non-parametric test. Student's t-test was performed as parametric test to compare different variables. For all statistical evaluations, a two-tailed probability of value $<0.05$ was considered significant.

\section{RESULTS}

\section{Age Distribution Table}

The mean age of the people in each group has no statistical significance ( $p>0.05)$. When compared non-parametrically into four groups, 2 -square test show no statistical $0-24$ years, $25-29,30-34$ and greater than 35 years the chi significance in each group is $(\mathrm{p}>0.05)$.

\section{Diagnosis}

On arranging the subjects according to the diagnosis shows almost same number of people fall in each group. Groups ( $p$ > 0.05) (Fig. 1). Drug requirement on analysing the calculated mean dose of induction agents, the $\mathrm{T}$ group shows significantly very high dose compared to P group ( $\mathrm{p}<0.001)$. But for the end point of induction to achieve, a lower dose than the calculated mean dose of thiopentone was needed and propofol group need to add excess drug, which was statistically significant $(p<0.05)$. The voltage of the stimulus has no statistical difference between the two groups ( $p>$ 0.05) (Table 2).

\section{The Initial Baseline Readings}

The initial baseline heart rate, systolic blood pressure, diastolic blood pressure, Mean Arterial Pressure (MAP), $\mathrm{SPO}_{2}$ were taken. Among these readings, only the diastolic blood pressure shows a significant statistical difference between the two groups $(\mathrm{p}<0.05)$. All other readings show no significant changes $(\mathrm{p}>0.05)$ (Table 3$)$.

\section{Heart Rate Variations after the Stimulus}

The readings from zero minute to $30^{\text {th }}$ minute are analysed. It was not significant at the zero minute $(p>0.05)$, whereas all the readings show very high significance among the groups ( $\mathrm{p}$ $<0.001$ ) (Table 4).

\section{Systolic Blood Pressure Distribution}

The changes at second minute was very highly significant between each other $(\mathrm{p}<0.001)$. All other readings show significant increase in systolic blood pressure in the thiopentone group $(\mathrm{p}<0.05)$ (Table 5).

\section{Diastolic Blood Pressure Distribution}

The readings at second minute and $30^{\text {th }}$ minute were significantly high for thiopentone group $(\mathrm{p}<0.05)$. Diastolic blood pressure at $6^{\text {th }}, 8^{\text {th }}$ and $15^{\text {th }}$ minute were highly significant for propofol $(\mathrm{p}<0.01)$ (Table 6).

\section{Mean Arterial Pressure Distributions (MAP)}

MAP at $4^{\text {th }} \mathrm{mt}, 8^{\text {th }} \mathrm{mt}$ and $30^{\text {th }} \mathrm{mt}$ shows a significant reduction for propofol $(\mathrm{p}<0.05)$ and that at $2^{\text {nd }}, 6^{\text {th }}$ and $15^{\text {th }} \mathrm{mt}$ were statistically highly significant $(\mathrm{p}<0.01$ ) (Figure 2 ).

\section{Rate Pressure Product}

There was a very highly significant reduction in RPP for propofol group compared to thiopentone group at $2^{\text {nd }} \mathrm{mt}$, $4^{\text {th }}$ $\mathrm{mt}, 8^{\text {th }} \mathrm{mt}, 10^{\text {th }} \mathrm{mt}$ and $30^{\text {th }} \mathrm{mt}(\mathrm{p}<0.001)$. The changes in other intervals were not that much significant $(p>0.05)$ (Table 7, Figure 3).

\section{Duration of Motor Seizure}

The duration of motor seizure has no statistical difference between the two groups ( $p>0.05$ ). But the time taken for recovery from anaesthesia were very less for propofol group compared with thiopentone. This was statistically highly significant $(\mathrm{p}<0.001)$ (Table 8).

\section{Adverse Effects}

Non-parametric comparison of adverse effects between the two groups shows no statistical significance ( $p>0.05$ ), but one patient each were reported for adverse effects from the thiopentone group ( $p>0.05$ ) (Table 9; Figure 4).

\begin{tabular}{|l|c|c|c|c|c|}
\hline & Drug & Mean & \pm SD & T value & P value \\
\hline \multirow{2}{*}{ Age (years) } & Thiopentone & 29.00 & 6.00 & \multirow{2}{*}{0.674} & $>$ \\
\cline { 2 - 6 } & Propofol & 28.15 & 5.25 & & \\
\hline \multirow{2}{*}{ Weight (kg) } & Thiopentone & 51.08 & 6.99 & \multirow{2}{*}{-5.726} & $<0.001$ \\
\cline { 2 - 4 } & Propofol & 59.70 & 6.47 & & \\
\hline
\end{tabular}

Table 1. Comparison of Age and Weight between Thiopentone and Propofol Groups

\begin{tabular}{|c|c|c|c|c|c|}
\hline & Drug & Mean & \pm SD & T value & P value \\
\hline \multirow{2}{*}{ Drug administered (mg) } & Thiopentone & 206.15 & 29.20 & \multirow{2}{*}{30.970} & \multirow{2}{*}{$<0.001$} \\
\hline & Propofol & 59.70 & 6.47 & & \\
\hline \multirow{2}{*}{ Extra drug administered (mg) } & Thiopentone & -2.40 & 24.62 & \multirow{2}{*}{-2.313} & \multirow{2}{*}{$<0.05$} \\
\hline & Propofol & 6.83 & 5.48 & & \\
\hline \multirow{2}{*}{ Succinylcholine administered (mg) } & Thiopentone & 25.29 & 3.57 & \multirow{2}{*}{-5.370} & \multirow{2}{*}{$<0.001$} \\
\hline & Propofol & 30.41 & 4.79 & & \\
\hline \multirow{2}{*}{ Extra succinylcholine administered (mg) } & Thiopentone & 3.88 & 6.55 & \multirow{2}{*}{3.972} & \multirow{2}{*}{$<0.001$} \\
\hline & Propofol & -1.33 & 5.03 & & \\
\hline Current (Millicoulomb) & Thiopentone & 203.00 & 84.80 & 1.131 & $>0.05$ \\
\hline \multicolumn{6}{|c|}{ Table 2. Drug and Stimulus requirement in Thiopentone and Propofol Groups } \\
\hline
\end{tabular}




\begin{tabular}{|c|c|c|c|c|c|}
\hline & Drug & Mean & \pm SD & T value & P value \\
\hline \multirow{2}{*}{ Heart rate (Beats per min.) } & Thiopentone & 84.55 & 8.21 & \multirow{2}{*}{0.343} & \multirow{2}{*}{$>0.05$} \\
\hline & Propofol & 83.85 & 9.95 & & \\
\hline \multirow{2}{*}{ Systolic BP (mmHg) } & Thiopentone & 119.38 & 9.49 & \multirow{2}{*}{-0.857} & \multirow{2}{*}{$>0.05$} \\
\hline & Propofol & 121.40 & 11.54 & & \\
\hline \multirow{2}{*}{ Diastolic BP (mmHg) } & Thiopentone & 73.60 & 7.96 & \multirow{2}{*}{-2.387} & \multirow{2}{*}{$<0.05$} \\
\hline & Propofol & 78.13 & 8.96 & & \\
\hline \multirow{3}{*}{ MAP (mmHg) } & Thiopentone & 88.23 & 6.71 & \multirow{3}{*}{-1.675} & \multirow{3}{*}{$>0.05$} \\
\hline & Propofol & 91.43 & 10.05 & & \\
\hline & Propofol & 96.90 & 1.08 & & \\
\hline
\end{tabular}

Table 3. Initial Baseline Readings in Thiopentone and Propofol Groups

\begin{tabular}{|c|c|c|c|c|c|}
\hline Time (min) & Drug & Mean & \pm SD & T value & P value \\
\hline \multirow{2}{*}{0} & Thiopentone & 88.30 & 13.26 & \multirow{2}{*}{1.611} & \multirow{2}{*}{$>0.05$} \\
\hline & Propofol & 82.88 & 16.66 & & \\
\hline \multirow{2}{*}{2} & Thiopentone & 98.40 & 14.47 & \multirow{2}{*}{5.186} & \multirow{2}{*}{$<0.001$} \\
\hline & Propofol & 80.70 & 16.02 & & \\
\hline \multirow{2}{*}{4} & Thiopentone & 102.10 & 16.49 & \multirow{2}{*}{4.566} & \multirow{2}{*}{$<0.001$} \\
\hline & Propofol & 85.48 & 16.07 & & \\
\hline \multirow[b]{2}{*}{6} & Thiopentone & 100.75 & 20.19 & \multirow{2}{*}{3.475} & \multirow{2}{*}{$<0.01$} \\
\hline & Propofol & 87.75 & 12.33 & & \\
\hline \multirow{2}{*}{8} & Thiopentone & 103.70 & 18.22 & \multirow{2}{*}{4.048} & \multirow{2}{*}{$<0.001$} \\
\hline & Propofol & 89.50 & 12.66 & & \\
\hline \multirow{2}{*}{10} & Thiopentone & 104.38 & 13.16 & \multirow{2}{*}{5.287} & \multirow{2}{*}{$<0.001$} \\
\hline & Propofol & 89.25 & 12.42 & & \\
\hline \multirow{2}{*}{15} & Thiopentone & 102.10 & 13.53 & \multirow{2}{*}{5.223} & \multirow{2}{*}{$<0.001$} \\
\hline & Propofol & 87.40 & 11.57 & & \\
\hline \multirow{2}{*}{30} & Thiopentone & 99.95 & 11.67 & \multirow{2}{*}{5.331} & \multirow{2}{*}{$<0.001$} \\
\hline & Propofol & 86.83 & 10.31 & & \\
\hline
\end{tabular}

\begin{tabular}{|c|c|c|c|c|c|}
\hline Time (min) & Drug & Mean & \pm SD & T value & P value \\
\hline \multirow{2}{*}{0} & Thiopentone & 122.33 & 13.83 & \multirow{2}{*}{1.412} & \multirow{2}{*}{$>0.05$} \\
\hline & Propofol & 117.53 & 16.46 & & \\
\hline \multirow{2}{*}{2} & Thiopentone & 135.10 & 22.48 & \multirow{2}{*}{3.751} & \multirow{2}{*}{$<0.001$} \\
\hline & Propofol & 118.35 & 17.10 & & \\
\hline \multirow{2}{*}{4} & Thiopentone & 129.88 & 16.48 & \multirow{2}{*}{2.323} & \multirow{2}{*}{$<0.05$} \\
\hline & Propofol & 120.98 & 17.77 & & \\
\hline \multirow{2}{*}{6} & Thiopentone & 127.45 & 19.57 & \multirow{2}{*}{2.208} & \multirow{2}{*}{$<0.05$} \\
\hline & Propofol & 119.33 & 12.60 & & \\
\hline \multirow{2}{*}{8} & Thiopentone & 130.40 & 23.12 & \multirow{2}{*}{1.772} & \multirow{2}{*}{$>0.05$} \\
\hline & Propofol & 123.00 & 12.77 & & \\
\hline \multirow{2}{*}{10} & Thiopentone & 126.78 & 17.53 & \multirow{2}{*}{1.703} & \multirow{2}{*}{$>0.05$} \\
\hline & Propofol & 121.35 & 9.94 & & \\
\hline \multirow{2}{*}{15} & Thiopentone & 124.55 & 12.16 & \multirow{2}{*}{2.393} & \multirow{2}{*}{$<0.05$} \\
\hline & Propofol & 118.83 & 9.00 & & \\
\hline \multirow{2}{*}{30} & Thiopentone & 122.58 & 12.10 & \multirow{2}{*}{1.295} & \multirow{2}{*}{$>0.05$} \\
\hline & Propofol & 119.55 & 8.48 & & \\
\hline
\end{tabular}

\begin{tabular}{|c|c|c|c|c|c|}
\hline Time (Min) & Drug & Mean & \pm SD & T value & P value \\
\hline \multirow{2}{*}{0} & Thiopentone & 74.73 & 11.84 & \multirow{2}{*}{0.675} & \multirow{2}{*}{$>0.05$} \\
\hline & Propofol & 72.88 & 12.67 & & \\
\hline \multirow{2}{*}{2} & Thiopentone & 81.58 & 18.56 & \multirow{2}{*}{2.405} & \multirow{2}{*}{$<0.05$} \\
\hline & Propofol & 73.18 & 11.97 & & \\
\hline \multirow{2}{*}{4} & Thiopentone & 80.73 & 13.76 & \multirow{2}{*}{1.938} & \multirow{2}{*}{$>0.05$} \\
\hline & Propofol & 74.85 & 13.35 & & \\
\hline \multirow{2}{*}{6} & Thiopentone & 82.05 & 11.64 & \multirow{2}{*}{3.173} & \multirow{2}{*}{$<0.01$} \\
\hline & Propofol & 74.50 & 9.54 & & \\
\hline \multirow{2}{*}{8} & Thiopentone & 84.40 & 18.40 & \multirow{2}{*}{2.764} & \multirow{2}{*}{$<0.01$} \\
\hline & Propofol & 75.48 & 8.87 & & \\
\hline \multirow{2}{*}{10} & Thiopentone & 78.38 & 11.65 & \multirow{2}{*}{1.780} & \multirow{2}{*}{$>0.05$} \\
\hline & Propofol & 74.45 & 7.67 & & \\
\hline \multirow{2}{*}{15} & Thiopentone & 78.90 & 8.91 & \multirow{2}{*}{2.725} & \multirow{2}{*}{$<0.01$} \\
\hline & Propofol & 73.55 & 8.65 & & \\
\hline \multirow{2}{*}{30} & Thiopentone & 79.60 & 8.73 & \multirow{2}{*}{2.375} & \multirow{2}{*}{$<0.05$} \\
\hline & Propofol & 75.05 & 8.40 & & \\
\hline
\end{tabular}




\begin{tabular}{|c|c|c|c|c|c|}
\hline Time (min) & Drug & Mean & \pm SD & T value & P value \\
\hline \multirow{2}{*}{0} & Thiopentone & 10793.35 & 2014.86 & \multirow{2}{*}{1.907} & \multirow{2}{*}{$>0.05$} \\
\hline & Propofol & 9786.48 & 2662.02 & & \\
\hline \multirow{2}{*}{2} & Thiopentone & 13264.78 & 2837.30 & \multirow{2}{*}{6.610} & \multirow{2}{*}{$<0.001$} \\
\hline & Propofol & 9514.78 & 2196.04 & & \\
\hline \multirow{2}{*}{4} & Thiopentone & 13228.15 & 2580.96 & \multirow{2}{*}{4.788} & \multirow{2}{*}{$<0.001$} \\
\hline & Propofol & 10369.80 & 2755.52 & & \\
\hline \multirow{2}{*}{6} & Thiopentone & 12844.38 & 3198.96 & \multirow{2}{*}{0.070} & \multirow{2}{*}{$>0.05$} \\
\hline & Propofol & 12683.75 & 14118.57 & & \\
\hline \multirow{2}{*}{8} & Thiopentone & 13665.80 & 3902.50 & \multirow{2}{*}{3.904} & \multirow{2}{*}{$<0.001$} \\
\hline & Propofol & 10996.93 & 1862.47 & & \\
\hline \multirow{2}{*}{10} & Thiopentone & 13252.03 & 2632.26 & \multirow{2}{*}{4.792} & \multirow{2}{*}{$<0.001$} \\
\hline & Propofol & 10843.78 & 1781.64 & & \\
\hline \multirow{2}{*}{15} & Thiopentone & 12719.63 & 2132.77 & \multirow{2}{*}{-0.190} & \multirow{2}{*}{$>0.05$} \\
\hline & Propofol & 13285.05 & 18664.21 & & \\
\hline \multirow{2}{*}{30} & Thiopentone & 12243.40 & 1863.73 & \multirow{2}{*}{5.124} & \multirow{2}{*}{$<0.001$} \\
\hline & Propofol & 10369.25 & 1370.58 & & \\
\hline
\end{tabular}

$\mathrm{RPP}=$ Systolic BP $\times$ Heart rate

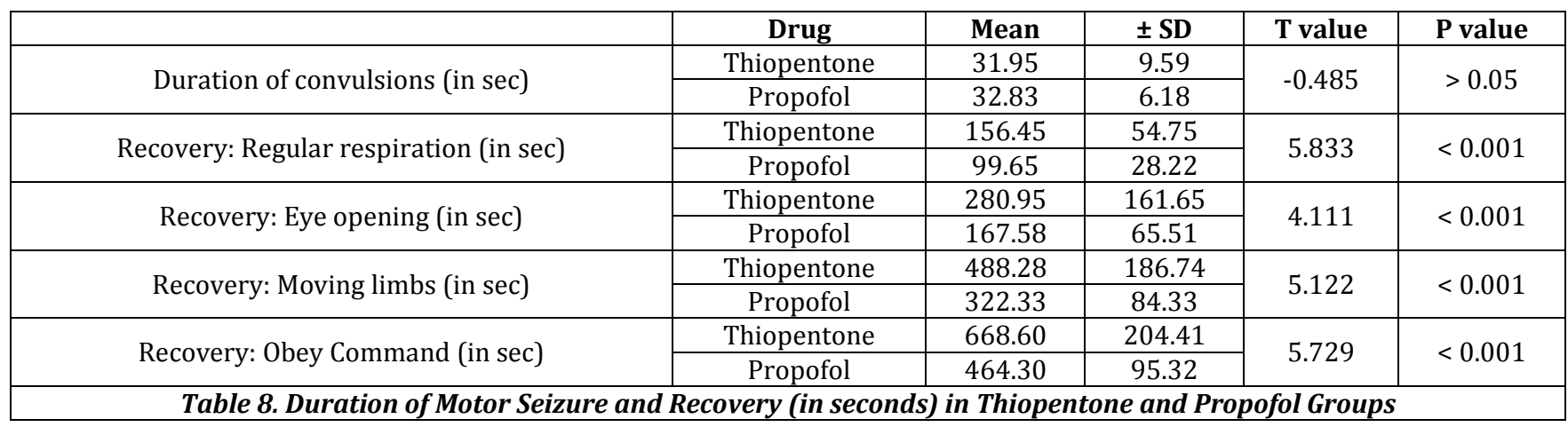

\begin{tabular}{|c|c|c|c|}
\hline Adverse Effects & Thiopentone & Propofol & Total \\
\hline \multirow{2}{*}{ Nil } & 37 & 40 & 77 \\
\hline & $92.50 \%$ & $100.00 \%$ & $96.30 \%$ \\
\hline \multirow{2}{*}{ Delirium } & 1 & \multirow[b]{2}{*}{-} & 1 \\
\hline & $2.50 \%$ & & $1.30 \%$ \\
\hline \multirow{2}{*}{ Loose Tooth } & 1 & \multirow{2}{*}{ - } & 1 \\
\hline & $2.50 \%$ & & $1.30 \%$ \\
\hline \multirow{2}{*}{ Restless } & 1 & \multirow{2}{*}{-} & 1 \\
\hline & $2.50 \%$ & & $1.30 \%$ \\
\hline
\end{tabular}

Chi square $=3.117 ; \mathrm{p}>0.05$
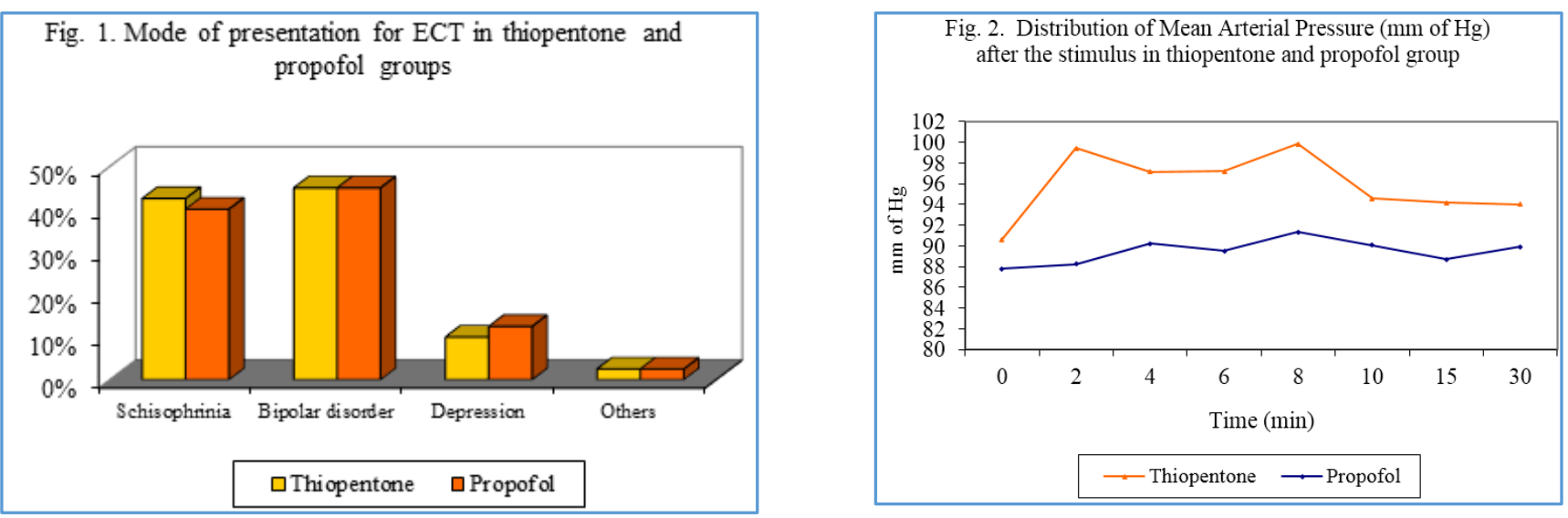

\section{DISCUSSION}

There was a statistically very high significant difference in weight of the subjects between groups ( $p<0.001$ ). The propofol group shows an increased mean weight compared to 
thiopentone. Reports by Noam (2004)(5) took the European population with a mean weight around $75.5 \mathrm{~kg}$. The calculated mean dose of thiopentone ( $\mathrm{T}-4 \mathrm{mg} / \mathrm{kg}$ ) was not needed to attain the anaesthetic plane. It took $2.40 \mathrm{mg}$ less than the calculated dose. In $\mathrm{P}$ group where the calculated dose is $1 \mathrm{mg} / \mathrm{kg}$, which cannot attain the adequate anaesthetic plane. The actual mean dosage needed for $\mathrm{P}$ group was $1.12 \mathrm{mg} / \mathrm{kg}$ and that for thiopentone was 3.4 $\mathrm{mg} / \mathrm{kg}$. There are reports of 2 dosages of thiopentone for ECT- $2 \mathrm{mg} / \mathrm{kg}$ and $4 \mathrm{mg} / \mathrm{kg}$ (Harti et al, 2001).(6) In Noam's study the dose of thiopentone was $3.6 \mathrm{mg} / \mathrm{kg}$ and that of propofol was $1.9 \mathrm{mg} / \mathrm{kg}$.(5) In a pilot study conducted before the present study, in which the dose of thiopentone used was $2 \mathrm{mg} / \mathrm{kg}$, but most of the patient's complaints of awareness during the procedure and show very high haemodynamic fluctuations.

Noam (2004)(5) used thiopentone $3 \mathrm{mg} / \mathrm{kg}$ and Vothknecht (2003) (7) gives us the dose of thiopentone as 3.3 $\mathrm{mg} / \mathrm{kg}$. But reports by Sakamoto (1999) ${ }^{(8)}$ shows a reduction in seizure duration associated with increasing doses of thiopentone, i.e. $2 \mathrm{mg} / \mathrm{kg}$ which gives a longer seizure duration than $4 \mathrm{mg} / \mathrm{kg}$. This reduction is seizure duration with a high dose of thiopentone may be the reason for opting a low-dose thiopentone for ECT. The medical fraternity has always tried for a balance between good patient clinical outcome and noncompliance. Regarding the dose of propofol, various dosage regimens were put forward for induction. Noam (2004),(6) Atsushira Sakamoto(8) (1999) Fumio Nishihara ${ }^{(9)}$ (2002) gave dosages of $1 \mathrm{mg} / \mathrm{kg}, 1.5 \mathrm{mg} / \mathrm{kg}, 2$ $\mathrm{mg} / \mathrm{kg}$ respectively. Kadoi(10) took propofol $1 \mathrm{mg} / \mathrm{kg}$ and succinylcholine for haemodynamic responses in ECT by echocardiography shows significant differences compared to the pre-induction levels ( $\mathrm{p}<0.05)$. Michail(11) in 1995 studied propofol $1.3-2 \mathrm{mg} / \mathrm{kg}$ vs methohexitone $1-1.9 \mathrm{mg} / \mathrm{kg}$ vs etomidate shows that propofol protects from untoward hypertensive response to ECT, which was least with etomidate. The present study took propofol $1.114 \mathrm{mg} / \mathrm{kg}$ for adequate induction. So a reduction in dose requirement by $2.40 \mathrm{mg}$ from the original calculated dose of thiopentone and additional requirement of $6.83 \mathrm{mg}$ of propofol shows a high statistical difference among the two groups. This suggests that ideal dose of thiopentone ranges between $3-4 \mathrm{mg} / \mathrm{kg}$ and that of propofol may range between $1-1.5 \mathrm{mg} / \mathrm{kg}$ for induction in ECT.

On observing the trends of heart rate, systolic pressure, diastolic pressure and MAP, there was some similarities regarding the maximum rise in values and maximum reduction from the initial values. There was a similar drop in systolic blood pressure, diastolic blood pressure and MAP from their initial mean values at the zero time. There was a similar maximum increase in diastolic blood pressure and MAP from their initial mean values at the $8^{\text {th }}$ minute. In systolic blood pressure, the maximum rise from the initial value for propofol was at the $8^{\text {th }}$ minute and that for thiopentone group are at the $2^{\text {nd }}$ minute. In case of the heart rate, the maximum reduction in $\mathrm{T}$ group occurs at zero time and that for $\mathrm{P}$ group occurs at $2^{\text {nd }}$ minute. So there was a reduction in heart rate, systolic blood pressure, diastolic blood pressure and MAP to the maximum towards the zero minute after procedure. This may be attributed to the vasodilatory action of the induction agents as well as the initial transient parasympathetic stimulation after ECT.(12,13) But the comparison at zero time such as heart rate, systolic blood pressure, diastolic blood pressure and MAP shows no much significance. This lack of significance may be attributed to the possible reduction in sensitivity of the automated blood pressure monitoring just after the end of the stimulus where the subjects were mostly at the tonic phase of convulsion.

Rate Pressure Product (RPP) is the product of heart rate and systolic blood pressure. It represents the myocardial oxygen demand. In comparison of the two groups shows no significant reduction at zero minute $(\mathrm{p}>0.05)$, which was the same in other readings such as heart rate, systolic blood pressure, diastolic blood pressure and MAP. The $2^{\text {nd }}, 4^{\text {th }}, 10^{\text {th }}$ and $30^{\text {th }}$ minute readings were highly significant $(p<0.001)$. The RPP of propofol group were definitely lower compared to T group. Propofol reduces the myocardial oxygen demand better than thiopentone. Along the same group, the RPP was maximum at the $8^{\text {th }}$ minute by $(+3572.22)$ and minimum at zero minute by +699.77 for thiopentone. The same for propofol was maximum at $15^{\text {th }}$ minute by +3111.60 and minimum at $2^{\text {nd }}$ minute by -658.61 . So propofol was successful to decrease the RPP from initial value during the sympathetic stimulation and reduces the myocardial oxygen demand. But Fumio Nishihara ${ }^{(9)}$ (2002) reports no significant difference between two age groups regarding MAP and RPP after ECT $(p>0.05)$.

\section{Strengths of the Study are}

The group was selected from a randomised numbered sample. The study is a double blinded one. The heart rate and blood pressure recordings were noted from an automated monitor, thus avoiding the observer bias. The pre-medicants and muscle relaxants used were same for both groups. All the subjects were preloaded with normal saline prior to the procedure to correct fluid deficit, which might have occurred from overnight fasting. This avoided the exaggerated haemodynamic fluctuations during induction due to fluid deficit. The stop watch used were same for all the subjects to detect the recovery time. All the readings were taken by the same anaesthetist; this avoided bias due to technical defect by different person.

\section{Limitations of the Study are}

The blood pressure monitoring was done by Cuff method. More accurate values might be obtained if intra-arterial blood pressure recordings were employed. Study limited over rather a younger age group populations. This prevents to study the haemodynamic change in all age groups. The study does not take into consideration of the drug therapy, in which the subjects were on. Their use of anticonvulsants, benzodiazepines and lithium can hinder the recovery time and seizure duration.

The readings were taken on the second ECT session. The changes in recovery and seizure duration may vary with each session. A comparison of both drugs in the same patient at different session could have given a more relevant result regarding the haemodynamics and recovery of drugs. This could have avoided the patient factors that interfere. We used different strength of the current in each group as stimulus. 
This can make variation in seizure duration as well as the recovery time and cognitive functions. No cardiovascular response prevention drugs such as Lignocaine, Nitroprusside, etc. were administered in both the groups, which might have lowered the haemodynamic responses. This is in good intention to find out the real changes in haemodynamic status during induction.

\section{CONCLUSION}

This double-blinded study using thiopentone $(4 \mathrm{mg} / \mathrm{kg}$ ) and propofol (1 $\mathrm{mg} / \mathrm{kg}$ ) shows that propofol offers better protection against wide fluctuations regarding haemodynamic parameters during and after ECT. Propofol offers an early recovery time from anaesthesia. The seizure duration was inconclusive, but shows a statistically insignificant improvement in the propofol group. The side effects were less in propofol group than thiopentone. Considering all the above parameters, propofol is a good quality anaesthetic agent for induction in ECT.

The maximum parasympathetic stimulation occurs between $0-2$ minutes and the maximum sympathetic stimulation occurs at $8^{\text {th }}$ minute after the stimulus. Further studies are needed to delineate the cognitive functions, seizure duration and dosage of the stimulus. There is scope for further investigations regarding the occurrence of parasympathetic and sympathetic stimulation during ECT. Further studies are required to improve the treatment modality for the wellbeing of society.

\section{REFERENCES}

[1] Izard P, Leclercq C, Ducassc JL. Use of propofol in 1350 anaesthetised patients for ECT. Ann TrAnesthReanim 1991;10(1):16-20.

[2] Bryson HM, Fulton BR, Faulds D. Propofol. An update of its use in anaesthesia and conscious sedation. Drugs 1995;50(3):513-59.

[3] Sackeim HA, Devanand DP, Prudic J. Stimulus intensity, seizure threshold, and seizure duration: impact on the efficacy and safety of electroconvulsive therapy. Psychiatr Clin North Am 1991;14(4):803-43.
[4] Stromgren LS, Dahl J, Fjeldborg N, et al. Factors influencing seizure duration and number of seizures applied in unilateral electroconvulsive therapy. Anaesthetics and benzodiazepines. Act Psychiar Scand 1980;62(2):158-65.

[5] Butterfield NN, Graf P, Macleod BA, et al. Propofol reduces cognitive impairment after electroconvulsive therapy. J ECT 2004;20(1):3-9.

[6] Harti A, Mamaouchi B, Idali H, et al. Anesthesia for electroconvulsive therapy: propofol versus thiopental. Encephale 2001;27(3):217-21.

[7] Vothknecht S, Kho KH, van Schaick HW, et al. Effects of maintenance electroconvulsive therapy on cognitive functions. J ECT 2003;19(3):151-7.

[8] Sakamoto A, Hoshino T, Suzuki N, et al. Effects of propofol anesthesia on cognitive recovery of patients undergoing electroconvulsive therapy. Psychiatry and Clinical Neurosciences 1999;53(6):655-60.

[9] Nishihara F, Saito S, Tobe M, et al. Hemodynamic changes during electroconvulsive therapy under propofol anesthesia. J Anesth 2002;16(4):332-5.

[10] Kadoi Y, Saito S, Ide M, et al. The comparative effects of propofol versus thiopentone on left ventricular function during electroconvulsive therapy. Anaesth Intensive Care 2003;31(2):172-5.

[11] Michail NA, Avramov MN, Husain MM. The comparative effects of methohexital, propofol, and etomidate for electroconvulsive therapy. Anesth Analg 1995;81(3):596-602.

[12] Hishaw I, Mc Keith IG. Propofol and ECT in patients at risk from acute intermittantprophysia. BJA 1998;80:262-6.

[13] Gajwani P, Muzina D, Gao K, et al. Awareness under anaesthesia during electroconvulsive therapy treatment. J ECT 2006;22(2):158-9. 